\title{
Metabolic responses of light and taste receptors - unexpected actions of GPCRs in adipocytes
}

\author{
Onyinye Nuella Ekechukwu' ${ }^{1}$ Mark Christian ${ }^{1}$ (i)
}

Accepted: 17 June 2021 / Published online: 1 July 2021

(c) The Author(s) 2021

\begin{abstract}
The G-protein-coupled receptor (GPCR) superfamily includes sensory receptors that can detect and respond to taste and light. Recent investigations have identified key metabolic roles for such receptors in tissues considered 'non-sensory' such as adipose tissue. The major functions of white and brown adipose tissues include energy storage/release and thermogenesis, respectively. These processes are tightly controlled by GPCR pathways that serve to maintain energy homeostasis. Opsins 3 and 4 are GPCRs activated by blue light and in adipocytes control lipolysis as well as affect brown adipocyte activity. Furthermore, Opsin 3 signals to regulate the conversion of white to thermogenic beige/BRITE (Brown-in-white) adipocytes. Taste receptors that respond to fatty acids, sweet and bitter are expressed in adipocytes as well as in taste buds. Ffar2 and the long chain fatty acid receptor GPR120 are highly expressed in white adipocytes and the human tongue. In adipose tissue Ffar 2 mediates the metabolic effects of butyrate and propionate produced by the gut microbiome. GPR 120 is highly expressed in brown adipose tissue and regulates fatty acid oxidation and mitochondrial function. The type I taste receptor Tas $1 \mathrm{r} 3$ senses sweet and umami, is expressed in adipocytes and on obesogenic diets Tas $1 \mathrm{r} 3$ global gene knockout protects from metabolic dysfunction. Type II taste receptors that sense bitter are expressed by adipocytes and bitter agonists have been found to modulate adipocyte differentiation and lipid storage levels. This review explores recent unexpected findings of light and taste receptors in adipocytes and examines effects of their signaling in the control of adipose tissue biology.
\end{abstract}

Keywords Brown adipose $\cdot$ White adipose $\cdot$ Opsins $\cdot$ Metabolism $\cdot$ GPCR

\section{Introduction}

Adipose tissues are connective tissues comprised mostly of adipocytes; fat containing cells whose primary functions are to store excess energy in the form of triglycerides. In addition to energy storage, they perform significant endocrine functions by secreting biologically active adipokines [1]. Adipose tissue is the largest endocrine organ in the body, producing a wide range of hormones that are involved in the regulation of metabolic process [2]. There are three types of adipose tissues: white adipose tissue (WAT) is the major site of energy storage, brown adipose tissue (BAT) facilitates non-shivering thermogenesis and beige/BRITE adipose tissue is a phenotypic intermediate of BAT and WAT that also has thermogenic functions [3]. The activities and biology of

Mark Christian

mark.christian@ntu.ac.uk

1 School of Science and Technology, Nottingham Trent University, Clifton Campus, Nottingham NG11 8NS, UK adipose tissues are controlled by the numerous $\mathrm{G}$ proteincoupled receptors (GPCRs) expressed on cell membranes and serve to modulate processes ranging from differentiation and browning to inflammation $[4,5]$.

In obese individuals, adipose tissue metabolic and endocrine functions are altered leading to the development of several common medical conditions, such as type 2 diabetes mellitus, cardiovascular diseases, non-alcoholic fatty liver, and even cancer [6]. With obesity, adipose tissues undergo adipocyte hypertrophy, infiltration by macrophages, oxidative stress, and increased cytokine production. This state of adipose tissues contributes to several obesity associated complications [7]. With an increasing global incidence of obesity the demands for novel approaches to its treatment and for its related comorbidities has ignited interest in discovering pathways that modulate adipocyte differentiation, storage, and lipolysis [8].

GPCRs comprise the largest group of receptors with more than 800 genes encoding the various receptors which are distributed across all the cells of the body [9]. They 
are transmembrane proteins made up of a single polypeptide chain with seven transmembrane alpha helices. Each receptor has an amino terminal domain located extracellularly, usually involved in ligand binding, and a carboxyl domain located on the intracellular side of the membrane facilitating downstream signaling [10]. Ligand binding or other stimuli initiate GPCR signaling, creating conformational changes in the GPCRs which results in the transfer of signals to intracellular targets by the activation of heterotrimeric G-proteins (comprising of $\alpha, \beta$, and $\gamma$ subunits) and other adjunct proteins. $G \alpha$ subunit proteins are grouped into four families: $\mathrm{Gs}, \mathrm{Gi} / \mathrm{o}, \mathrm{Gq}$ and $\mathrm{G}_{12 / 13}$. Interaction with an activated GPCR induces exchange of GDP to GTP on the $\mathrm{G} \alpha$ subunit, facilitating $\mathrm{G} \alpha$-GTP dissociation from the $\mathrm{G} \beta \gamma$ dimer and subsequent release of $\mathrm{G}$ proteins from the receptor [11]. Dissociated G protein subunits (Go-GTP and $\mathrm{G} \beta \gamma$ ) then interact with different downstream effectors and transduction pathways to mediate physiological functions.

GPCRs are classified into different families, each with variations in their structure and function [12]. The Rhodopsin family constitutes the largest GPCR family and encompasses receptors for odorants and small ligands such as fatty acids. It includes opsins that respond to specific light wavelengths in the presence of a chromophore. The Secretin receptor family have a characteristic large $\mathrm{N}$-terminal ectodomain and are activated by ligands such as glucagon and calcitonin. The Metabotropic glutamate receptor family includes GABA-B receptors, olfactory receptors, and taste receptors.

This review explores recent findings concerning GPCRs that are expressed on adipocytes and examines the effects of their signaling in the control of adipose tissue biology. BAT is a specialized thermoregulatory tissue that dissipates free fatty acids [13] into heat and represents an important target for obesity treatment under the control of GPCR-stimulated pathways. The canonical pathway for brown fat activation, in response to cold, is primarily through the sympathetic nervous system release of norepinephrine and activation of the $\beta 3$-adrenergic receptor [14]. This cAMP-dependent pathway activates lipolysis and induces the expression and activation of uncoupling protein 1 (UCP1) to generate heat by dissipation of the mitochondrial proton gradient [13]. UCP1dependent thermogenesis also occurs in WAT following the process of browning in white adipocytes which, under the influence of physiological or pharmacological stimuli, are converted into UCP1-expressing beige or brown-in-white (BRITE) adipocytes [15]. Identification of pathways that can induce thermogenesis and/or promote browning have potential to be utilized for modulating energy balance to treat obesity and associated metabolic diseases [16]. Of particular interest are the recent studies that have found adipocyte GPCRs activated by stimuli not necessarily considered directly relevant to adipose tissue regulation. Receptors such as those involved in light and taste sensing have unexpectedly been found in adipose tissue and adipocytes and have profound effects on cells and tissue function and whole-body metabolism.

\section{Opsins}

\subsection{Opsin 3}

The opsin family of GPCRs serve as light detectors in animals. Of these, Opsin 3 (Opn3, encephalopsin) is a relatively poorly characterised transmembrane photoresponsive heptahelical GPCR. It is expressed in adipose tissues [17] and has the potential to mediate non-visual photoreceptive actions. In response to high fat diet Opn3 is downregulated in epididymal WAT [18]. Recent findings indicate that this receptor has an important role in brown and white adipocytes where it modulates cellular metabolic processes [17, 19]. Mice in which the $O p n 3$ gene is knocked out are more prone to diet-induced obesity and insulin resistance [19]. The importance of BAT in the metabolic role of Opn3 is indicated by knockout mice presenting with impaired maximum thermogenic capacity along with lower levels of heat production in response to norepinephrine. Investigation of the cell autonomous actions of Opn3 in cultured brown adipocytes revealed that in knockout cells glucose uptake was decreased and there was lower nutrient-induced mitochondrial respiration compared to wild type cells. Interestingly, although glucose uptake was reduced in the absence of $O p n 3$, fatty acid uptake was enhanced. However, the utilization of fatty acids as an energy substrate is likely perturbed by reduced mitochondrial number in $O p n 3-\mathrm{KO}$ brown adipocytes leading to blunted mitochondrial respiration [19].

OPN3 contains sequence motifs characteristic of a photoresponsive receptor raising the possibility that light exposure could modulate metabolic parameters. Exposing cultured brown adipocytes to light increases glucose uptake and glucose-dependent mitochondrial respiration in wild type cells. However, in Opn3-KO cells the effect of light on these parameters was almost completely blunted, supporting the requirement for OPN3 in the response of brown adipocytes to light. It is noteworthy that at the cellular level there was decreased glucose uptake in Opn3KO compared to wild type cells even when cultured in darkness indicating a basal level of OPN3 activity or a response to stimuli other than light. At the molecular level, a key gene affected by light and dependent on Opn3 expression is CPT1 which facilitates carnitine-dependent transport of fatty acids into mitochondria. In vivo light exposure of mice revealed that white light increases brown fat energy expenditure supporting a thermogenic role for OPN3. Mechanistically, OPN3 may activate brown 
adipocytes through Gos and the PKA pathway, which has been reported in airway smooth muscle cells [20]. Furthermore, in the absence of the Opn3 gene, the mitochondria in BAT present with disorganized organellar cristae indicating OPN3 has a key role in mitochondrial organization and/or maintenance [17]. The absence of Opn3 in inguinal WAT results in reduced expression of genes associated with lipolysis (hormone-sensitive lipase, adipose triglyceride lipase, and perilipin) as well as UCP1 and the transcription co-factor PGC-1 $\alpha$ [17] (Fig. 1).

Maintenance of wild type mice in the absence of blue light (minus $480 \mathrm{~nm}$ ), to reduce photon flux for OPN3 activation, results in reduced BAT levels of UCP1 [17] further supporting the role of opsins in control of gene expression and function of this tissue. Non-shivering thermogenesis to maintain body temperature with cold exposure is impaired in Opn3 KO mice as well as wild type mice maintained under minus blue light conditions [17]. Although it is clear that
OPN3 has profound effects on BAT function, evidence indicates that its primary site of action is WAT where it determines lipolysis rates and ultimately controls substrate availability for BAT [17]. Blue light stimulates white adipocytes by promoting elevated cAMP and HSL phosphorylation which was absent in Opn3 KO cells [17]. White rather than brown adipose tissue being the major site of OPN3 action is supported by its much greater expression in WAT compared to BAT [21]. The high expression in WAT is supported by analysis of our own datasets in which Opn3 is at significantly higher levels in BAT compared to subcutaneous WAT or mesenteric WAT from mice maintained at $28{ }^{\circ} \mathrm{C}$ [22]. This analysis did not reveal differential expression between subcutaneous and mesenteric WAT, but further analysis is required to determine if the expression of Opn3 differs between WAT depots, particularly subcutaneous WAT and the deeper visceral WAT depots that may receive lower levels of exposure to blue light.

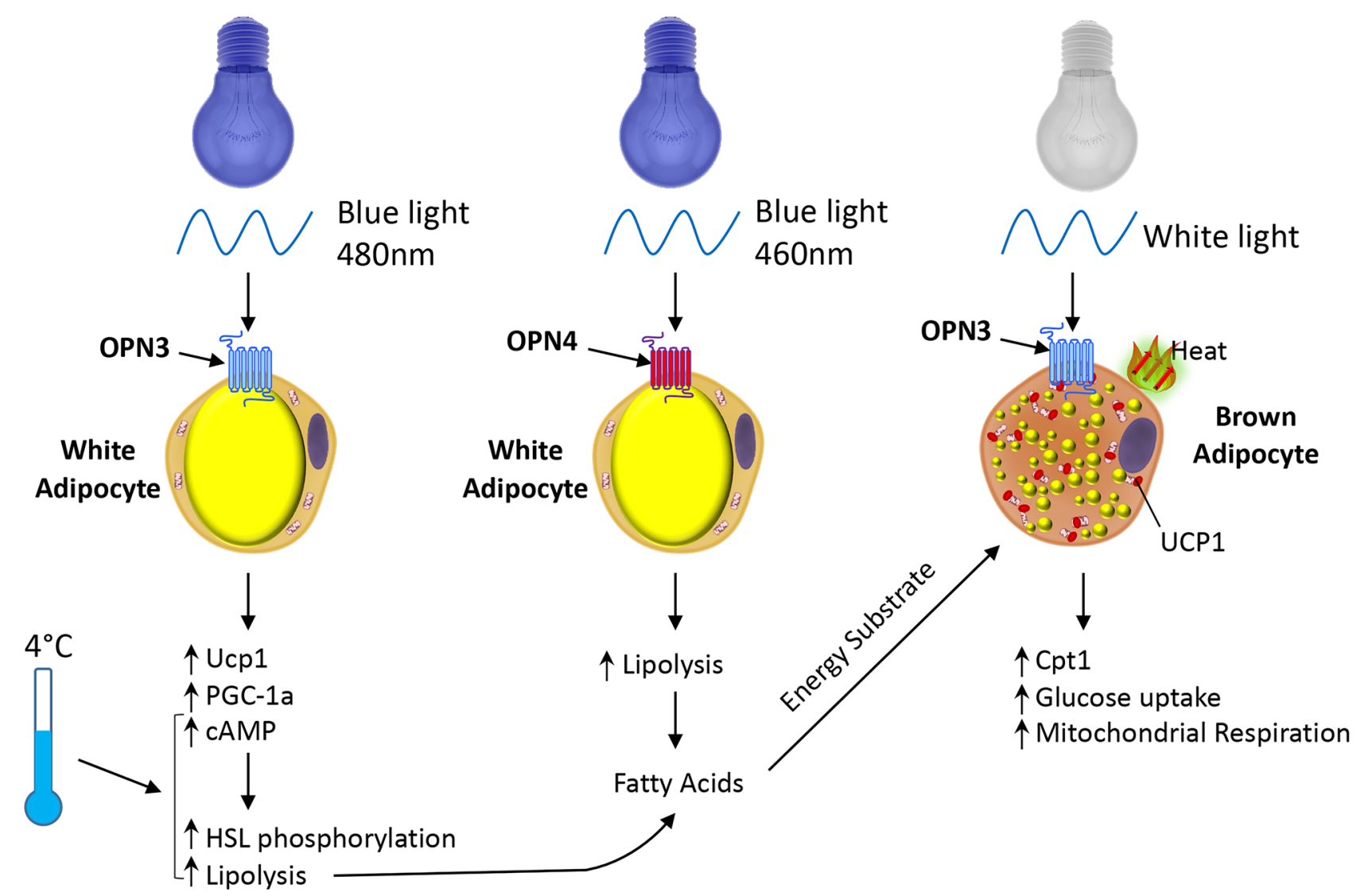

Fig. 1 OPN3 and OPN4 mediate effects of light exposure on adipocyte metabolism. Exposure of brown adipocytes to white light, through the action of Opsin 3 (OPN3) increases expression of Cpt1, along with increased mitochondrial respiration and glucose uptake. OPN3 activation in white adipocytes by blue light $(480 \mathrm{~nm})$ induces expression of uncoupling protein 1 (Ucp1) and PGC-1 $\alpha$, indicative of conversion to a beige/BRITE phenotype. OPN3 is required for normal lipolysis in response to cold exposure through induction of cAMP and phosphorylation of hormone sensitive lipase (HSL). Similarly, OPN4 in white adipocytes is required for normal lipolysis through phosphorylation of HSL. The fatty acids released by lipolysis provide an energy substrate for BAT thermogenesis as well as directly activating UCP1 


\section{$2.20 p \sin 4$}

Other members of the Opsin family have been found to impact WAT and BAT function. Opsin 4 (Opn4, melanopsin) has been detected in both 3T3-L1 adipocytes and human subcutaneous WAT [23]. This receptor mediates the effects of blue light exposure of adipocytes causing increased rate of basal lipolysis and reduced lipid droplet size through coupling to transient receptor potential canonical cation channels [23]. Within the visible light spectrum approximately $40 \%$ is in the blue/green wavelength range and it is estimated that $1-5 \%$ of this may reach the subcutaneous adipose tissue [23]. Therefore, it is likely that physiological light intensities on a sunny day can penetrate the skin to activate OPN4 in adipose tissues.

\subsection{Opsin 5}

A further example, Opsin 5 (Opn5, neuropsin), which is sensitive to visible violet light acts to suppress thermogenesis. Unlike OPN3, OPN5 acts from glutamatergic neurons in the hypothalamic preoptic area (POA) [24]. These Opn5 POA neurons project to the BAT and act to reduce thermogenesis. Furthermore, in Opn5 knockout mice BAT activity is enhanced resulting in increased body temperature and upon cold exposure the thermogenic response is exaggerated [24].

The experimental data revealing actions of light-sensitive proteins in tissues within the body which are exposed to low amounts of light raises the question of the real-life functional roles of extraocular light sensors within internal tissues. One possibility is that receptors such as OPN3 may be involved in the control and synchronization of the clock system in peripheral tissues. Current data does not support such a role [19], but warrants further investigations of the interaction of OPN3 and the clock genes. It is possible that OPN3 and other peripheral light sensors explain the metabolic dysfunctions that have been reported with exposure to light at night, jet lag and shift work [25-27].

\section{Nutrient and taste receptors}

\subsection{GPR120}

GPR120 also known as free fatty acid receptor 4 (Ffar4) was deorphanized in 2005 and is responsive to long chain fatty acids [28, 29]. This GPCR serves an important role in the sensing and preference for fatty acids due to its expression in type II taste buds [30, 31]. In addition, it plays important roles in immune responses by mediating the anti-inflammatory actions of $\omega-3$ fatty acids as well as controlling energy metabolism and hormone regulation [32]. Ablation of the
Ffar4 gene in mice leads to obesity, glucose intolerance and hepatic steatosis [33]. GPR120 is expressed in adipose tissues, higher in obese compared to lean human subjects, and a mutation with decreased signaling capacity is associated with increased risk of obesity [33]. GPR120 is highly expressed in BAT and cold exposure increases its expression in both murine BAT and subcutaneous WAT [22].

Stimulation of GPR 120 has been demonstrated to increase the activities of BAT, with results showing increased thermogenesis and browning of WAT in mice [34, 35]. GPR 120 signaling leads to increased circulating levels of FGF21 [34]. Furthermore, neonatal survival is impacted by GPR120-dependent induction of thermogenesis through UCP1 expression and fatty acid oxidative capacity as well as FGF21 levels [36].

Treatment of mice with the selective GPR120 ligand TUG-891 increases fatty acid oxidation, reduces fat mass coincident with decreased brown adipocyte lipid content and increased nutrient uptake by BAT [35] consistent with BAT activation. Mechanistically, TUG-891 acutely induces $\mathrm{O}_{2}$ consumption in brown adipocytes and through GPR120dependent calcium release promotes mitochondrial depolarization and fission [35]. This mechanism is dependent on signaling through Gq. However, recent findings indicate that GPR120 can also signal via Gi as part of an autocrine negative feedback mechanism to regulate lipolysis by the released free fatty acids [37].

\subsection{FFAR2}

Free fatty acid receptor 2 (Ffar2 or Gpr43) is activated by short chain fatty acids (SCFAs) such as butyrate, acetate, and propionate. Although not extensively studied as an oral taste receptor it has been detected in fungiform papillae of the human tongue [38]. As SCFAs have a sour taste [39] it may be difficult to clearly delineate the role FFAR2 in taste perception. Global ablation of the Ffar2 gene has revealed contradictory findings on its metabolic role. One study found that ablation of the gene protects mice from fat mass gain on a high fat diet along with improved glucose control [40]. Interestingly, these $\mathrm{KO}$ mice have higher energy expenditure and increased core body temperature, although BAT UCP1 expression was reported to be unaffected. In contrast, a further study showed that Ffar2-deficient mice become obese on a normal diet [41]. FFAR2 promotes suppression of insulin signaling in adipocytes to prevent fat accumulation and transgenic mice expressing FFAR2, selectively in adipose tissue, remain lean even on a high fat diet [41]. The contradictory findings concerning Ffar 2 knockouts may be a consequence of variation in the gut microbiota in different environments or due to differences in the mouse genetic backgrounds. 
The major source of SCFAs is from the anaerobic fermentation of non-digestible dietary fibers by gut-resident microorganisms. The most abundant phyla in the intestine are the gram-negative Bacteroidetes and the gram-positive Firmicutes. Acetate and propionate are produced by Bacteroidetes, and Firmicutes mostly produce butyrate [42, 43]. Clinical investigations following intervention with dietary supplements to increase gut-derived propionate have revealed metabolic benefits including reduced body weight gain and lower intra-abdominal fat accretion [44]. Propionate supplementation has also been found to raise resting energy expenditure and lipid oxidation in humans [45]. Focusing on SCFA action in cultured murine brown adipocytes the FFAR2 agonist acetate was found to upregulate UCP1 and PGC- $1 \alpha$ and promote mitochondrial biogenesis [46]. Furthermore, in vivo exposure to nanoparticle-delivered acetate enhances white fat browning and increases thermogenic capacity along with reduced adiposity [47]. Taken together, these findings support SCFAs serving to activate BAT and promote the BRITE adipocyte programme.

\section{Bitter and sweet taste receptors}

GPR120 and FFAR2 are not the only examples of GPCR taste receptors with important effects in adipocytes. Both bitter and sweet taste receptors have been detected in non-oral tissues including adipose tissues. Bitter agonists that activate type II taste receptors (TAS2Rs) have been found to modulate adipocyte differentiation and depletion of the $\alpha$-subunit of the gustatory $\mathrm{G}$ protein gustducin protects against obesity on high fat diet with increased BAT activity [48]. Some reports reveal that bitter agonists, such as quinine, promote primary mouse adipocyte differentiation, being at least partly dependent on the GPCR TAS2R106 [49]. In contrast, treatment with quinine or denatonium benzoate decreased adipocyte differentiation of 3T3-F442A cells [48]. The bitter taste receptor TAS2R38 is expressed by human white adipose tissue and adipocytes. Higher levels are detected in subcutaneous and visceral adipose tissue from obese compared to lean subjects and expression increases during adipogenesis [50]. Furthermore, the TAS2R38 bitter agonist 6-n-propylthiouracil promotes delipidation of adipocytes

Table 1 Taste receptors expressed in adipose tissue and cultured adipocytes

\begin{tabular}{|c|c|c|c|}
\hline Taste Receptor & White Adipose Tissue & Brown Adipose Tissue & Cell Line \\
\hline Ffar2/Gpr43 & $\begin{array}{l}\text { [21], Mesenteric, subcutaneous, \& epididymal } \\
\text { [59], subcutaneous, perirenal, mesenteric, } \\
\text { epididymal [60] }\end{array}$ & {$[21][21]$} & $\begin{array}{l}\text { IMBAT brown adipocyte [46], 3T3-L1 [60], } \\
\text { 3T3-L1 [61], mouse white primary adipo- } \\
\text { cytes [21] }\end{array}$ \\
\hline Ffar3/Gpr41 & & & human subcutaneous primary adipocytes [62] \\
\hline Ffar4/Gpr120 & $\begin{array}{l}\text { [21], Subcutaneous, gonadal, mesenteric [22, } \\
\text { 63]. Human subcutaneous and omental [33] }\end{array}$ & {$[21,22,63]$} & $\begin{array}{l}\text { IMBAT brown adipocyte [46], human sub- } \\
\text { cutaneous primary adipocytes [62], mouse } \\
\text { white primary adipocytes [21] }\end{array}$ \\
\hline Gpr84 & Epididymal [64], subcutaneous [65] & {$[65]$} & $\begin{array}{l}\text { 3T3-L1 [64], human omental primary adipo- } \\
\text { cytes [64], human subcutaneous primary } \\
\text { adipocytes [62] }\end{array}$ \\
\hline hTAS1R3/mTas1r3 & $\begin{array}{l}\text { [58], human gluteal and abdominal subcuta- } \\
\text { neous [66] }\end{array}$ & & 3T3- L1 [58] \\
\hline hTAS2R4/mTas2r108 & $\begin{array}{l}\text { [52] Subcutaneous, Gonadal \& Mesenteric } \\
\text { [48] }\end{array}$ & {$[52]$} & 3T3-L1 [52], 3T3-F422A [48] \\
\hline hTAS2R41/mTas2r126 & {$[52]$} & {$[52]$} & 3T3-L1 [52] \\
\hline $\begin{array}{l}\text { hTAS2R43 } \\
\text { hTAS2R45 } \\
\text { hTAS2R46 } \\
\text { hTAS2R31 } \\
\text { hTAS2R14 } \\
\text { hTAS2R19 } \\
\text { hTAS2R7 }\end{array}$ & $\begin{array}{l}\text { Human gluteal and abdominal subcutaneous } \\
\text { [66] }\end{array}$ & & \\
\hline mTas2r134 & & {$[52]$} & \\
\hline hTAS2R60/mTas2r135 & $\begin{array}{l}\text { [52] Subcutaneous, Gonadal \& Mesenteric } \\
\text { [48] }\end{array}$ & {$[52]$} & 3T3-L1 [52], 3T3-F422A [48] \\
\hline hTAS2R3/mTas2r137 & {$[52]$} & {$[52]$} & 3T3-L1 [52] \\
\hline hTAS2R38/mTas2r138 & {$[52]$} & & \\
\hline mTas2r143 & {$[52]$} & {$[52]$} & 3T3-L1 [52] \\
\hline
\end{tabular}

Gene orthologs from [51] 
[50]. There are many members of the TAS2R family [51] with several reported to be expressed in murine BAT and WAT as well as adipocyte cell lines [52]. A summary of the taste receptors reported to be expressed in adipose tissue and adipocytes is shown in Table 1.

Type I taste receptors (T1Rs) that are largely responsible for sweet and umami taste have been reported in adipose tissue and adipocytes to have roles in the regulation of cellular metabolism [53]. Global gene knockout mouse studies have revealed that T1Rs have important metabolic actions. On a standard chow diet lack of Tas $1 r 3$ greatly impairs glucose clearance [54]. In contrast, on obesogenic diets the absence of T1Rs confers metabolic benefits. Tas $1 r 3 \mathrm{KO}$ mice were found to be resistant to obesity when their diet was supplemented with $34 \%$ sucrose solution [55]. Several investigations have found that knockout of Tas1r2 or Tas $1 r 3$ prevents accumulation of fat in adipose tissue and liver, as well protection from hyperinsulinemia $[56,57]$. As these studies utilised global gene knockouts it is unclear which tissues mediate the metabolic effects. Adipocytes are potentially important as the expression of T1Rs has been detected in 3T3-L1 cells [58]. Tas1r3 showed a marked induction during the process of adipogenesis and treatment with sucralose or saccharin inhibited differentiation in a Tas1r3-dependent manner. Further studies are necessary to fully determine the roles of these extra oral taste receptors in adipocyte biology and their consequences on cellular metabolism.

\section{Discussion}

Recent findings demonstrate that light and taste GPCRs play crucial roles in the control of adipose tissue biology. This highlights the different actions of these receptors in the modulation of lipolysis, glucose uptake, adipogenesis and browning. Thus, these GPCRs represent valid targets for potential therapeutic agents aimed at managing obesity and improving the outcomes of its complications such as type 2 diabetes and cardiovascular diseases. Many therapeutic agents (as much as 30-50\%) already mediate their effects through the activation/signaling of different GPCRs distributed across the tissues/cells of the body [67]. A recent analysis of GPCR expression in visceral mouse adipose tissue identified the expression of 288 receptors [68]. Of these, only 114 GPCR transcripts had a transcripts per million (TPM) value above 1.0. Further inspection of the data supports the findings explored in this review with Ffar2 being the $10^{\text {th }}$ most highly expressed GPCR in mouse WAT and GPR120 expression detected. Of the Opsins, only Opn3 had a TPM greater than 1.0 and the most highly expressed taste receptor from this study was Tas1r3 [68]. Many of the GPCRs expressed on the surface of adipose tissues are orphans, with little known about their functions or the ligands/physical stimuli that activate them. For example, from a qRT-PCR study, the majority of the 163 GPCRs detected in subcutaneous adipose tissue have unknown effects on adipose tissue biology [4]. As adipose tissue is heterogenous in nature gene expression analysis does not necessarily implicate adipocyte expression. The application of single cell RNAseq to adipose tissues will be a valuable technology to determine the specific cell types that express metabolically relevant GPCRs. Identification of adipocyte GPCRs as well their activators will provide a better understanding of the signaling processes to facilitate development of more potent targets for reducing adipocyte hypertrophy and inflammation which contributes to the development of obesity and its complications.

Targeting the fatty acid taste receptors could be achieved through dietary interventions, including supplements, and pharmaceuticals. Activation of FFAR2 can be achieved through dietary modulation, for example supplementation with inulin propionate ester to increase colonic levels of propionate, which has metabolic benefits [44]. In addition, several pharmacological ligands have been developed that activate FFAR2 [69-71]. The thiazolidine FFAR2 orthosteric agonist TUG-1375 has high solubility, favourable pharmacokinetic properties and is 50 -fold more potent than propionate at inhibiting lipolysis in murine adipocytes [71]. Hence, this compound warrants further exploration in the context of developing new FFAR2 agonists as potential treatments of inflammatory and metabolic diseases. The endogenous ligands for GPR120 are $\omega-3$ polyunsaturated fatty acids present in fish oils. However, it is likely that the amount of fish oil required to provide sustained GPR120 activation to achieve clinical benefit is impractical. Accordingly, development of pharmacological ligands provides a way to enhance GPR120 signaling to improve metabolic health. GPR120selective agonists such as TUG-891 or its derivative cpdA have proved to be effective in mouse studies, with cpdA having anti-inflammatory effects and improving glucose and insulin responses [72]. Further novel ligands have been developed that activate GPR $120[73,74]$ and provide new directions and opportunities for obesity treatment.

The unexpected findings that adipocytes express both bitter and sweet taste receptors add them to the set of GPCRs expressed in both taste buds and adipocytes including the fatty acid receptors. The extra-oral bitter taste receptors expressed in adipose tissue may indicate a potential site of action of bitter components of traditional medicines [51]. Therefore, a comprehensive evaluation of the active constituents of traditional medicines, particularly with a bitter taste, warrants investigations of effects on adipose tissue and in vitro cultured adipocytes.

Opsins as receptors that can modulate adipocyte metabolism in a cell autonomous manner is unexpected given that the level of light exposure of adipose tissue is low. However, 
researchers have estimated that $1-5 \%$ of visible light will reach subcutaneous adipose tissue [23]. The deeper visceral adipose depots also express Opn3, so this raises the question of the degree of activation of the receptor in these tissues and could the reduced level of light exposure of visceral depots contribute to adverse metabolic impact of visceral fat? The actions of opsins in adipose tissue may contribute to increased levels of obesity and metabolic dysfunction associated with shift work [75]. OPN3 directly binds the chromophore retinal and interacts with melanocortin 1 receptor to facilitate functional responses [76]. As melanocortin receptors are detectable in adipose tissue [77], it raises the possibility that this interaction or with other receptors may contribute to the downstream effects of light through adipose opsins.

\section{Conclusion}

Many GPCRs which are expressed on adipocytes play vital roles in the modulation and control of adipose tissue biology and whole-body energy homeostasis. The recent findings that highlight the roles of light and taste responsive GPCRs provide new directions to modulate fat storage, release, and adipocyte browning. More in depth knowledge and understanding of these receptors, their signaling pathways and downstream functions, may lead to new therapeutic interventions to more effectively manage obesity, metabolic disorders and associated co-morbidities.

Funding MC received funding from BBSRC grant BB/P008879/2.

\section{Declarations}

Conflicts of interest The authors have no conflicts of interest to declare.

Open Access This article is licensed under a Creative Commons Attribution 4.0 International License, which permits use, sharing, adaptation, distribution and reproduction in any medium or format, as long as you give appropriate credit to the original author(s) and the source, provide a link to the Creative Commons licence, and indicate if changes were made. The images or other third party material in this article are included in the article's Creative Commons licence, unless indicated otherwise in a credit line to the material. If material is not included in the article's Creative Commons licence and your intended use is not permitted by statutory regulation or exceeds the permitted use, you will need to obtain permission directly from the copyright holder. To view a copy of this licence, visit http://creativecommons.org/licenses/by/4.0/.

\section{References}

1. MacDougald OA, Burant CF. The Rapidly Expanding Family of Adipokines. Cell Metab. Cell Metab. 2007. p. 159-61. Available from: https://pubmed.ncbi.nlm.nih.gov/17767903/.
2. Coelho M, Oliveira T, Fernandes R. Biochemistry of adipose tissue: An endocrine organ. Arch Med Sci. Termedia Publishing; 2013. p. 191-200. Available from: /pmc/articles/PMC3648822/.

3. Giralt M, Villarroya F. White, brown, beige/brite: Different adipose cells for different functions? Endocrinology. Endocrinology; 2013. p. 2992-3000. Available from: https://pubmed.ncbi.nlm.nih. gov/23782940/.

4. Amisten S, Neville M, Hawkes R, Persaud SJ, Karpe F, Salehi A. An atlas of G-protein coupled receptor expression and function in human subcutaneous adipose tissue. Pharmacol Ther. Elsevier BV; 2015;146:61-93. Available from: https://pubmed.ncbi.nlm. nih.gov/25242198/.

5. Im H, Park JH, Im S, Han J, Kim K, Lee YH. Regulatory roles of G-protein coupled receptors in adipose tissue metabolism and their therapeutic potential. Arch Pharm Res. Pharmaceutical Society of Korea; 2021. p. 133-45. Available from: https://pubmed.ncbi.nlm. nih.gov/33550564/.

6. Longo M, Zatterale F, Naderi J, Parrillo L, Formisano P, Raciti $\mathrm{GA}$, et al. Adipose tissue dysfunction as determinant of obesityassociated metabolic complications. Int J Mol Sci. MDPI AG; 2019;20. Available from: /pmc/articles/PMC6539070/.

7. van Diepen JA, Robben JH, Hooiveld GJ, Carmone C, Alsady M, Boutens L, et al. SUCNR1-mediated chemotaxis of macrophages aggravates obesity-induced inflammation and diabetes. Diabetologia. Springer Verlag; 2017;60:1304-13. Available from: https:// pubmed.ncbi.nlm.nih.gov/28382382/.

8. Chooi YC, Ding C, Magkos F. The epidemiology of obesity. Metabolism. W.B. Saunders; 2019;92:6-10. Available from: https://pubmed.ncbi.nlm.nih.gov/30253139/.

9. Kroeze WK, Sheffler DJ, Roth BL. G-protein-coupled receptors at a glance. J Cell Sci. The Company of Biologists Ltd; 2003;116:4867-9. Available from: http://pdsp.cwru.edu.

10. Hanlon CD, Andrew DJ. Outside-in signaling - A brief review of GPCR signaling with a focus on the Drosophila GPCR family. J Cell Sci. Company of Biologists Ltd; 2015. p. 3533-42. Available from: https://pubmed.ncbi.nlm.nih.gov/26345366/.

11. Hepler JR, Gilman AG. G proteins. Trends Biochem Sci. Trends Biochem Sci; 1992;17:383-7. Available from: https://pubmed. ncbi.nlm.nih.gov/1455506/.

12. Rosenbaum DM, Rasmussen SGF, Kobilka BK. The structure and function of G-protein-coupled receptors. Nature. NIH Public Access; 2009. p. 356-63. Available from:/pmc/articles/PMC3967846/.

13. Cannon B, Nedergaard J. Brown Adipose Tissue: Function and Physiological Significance. Physiol Rev. 2004;84:277-359.

14. Cao W, Daniel KW, Robidoux J, Puigserver P, Medvedev AV, Bai X, et al. p38 Mitogen-Activated Protein Kinase Is the Central Regulator of Cyclic AMP-Dependent Transcription of the Brown Fat Uncoupling Protein 1 Gene. Mol Cell Biol. Department of Psychiatry, Duke University Medical Center, Durham, North Carolina 27710, USA.; 2004;24:3057-67. Available from: http:// www.ncbi.nlm.nih.gov/entrez/query.fcgi? $\mathrm{cmd}=$ Retrieve $\& \mathrm{db}=$ PubMed\&dopt $=$ Citation\&list_uids $=15024092$.

15. Rosenwald M, Perdikari A, Rülicke T, Wolfrum C. Bi-directional interconversion of brite and white adipocytes. Nat Cell Biol. Institute of Food, Nutrition and Health, ETH Zurich, Schwerzenbach, Switzerland.; 2013;15:659-67. Available from: http://www.ncbi. nlm.nih.gov/pubmed/23624403.

16. Kim SH, Plutzky J. Brown fat and browning for the treatment of obesity and related metabolic disorders. Diabetes Metab J. Korean Diabetes Association; 2016. p. 12-21. Available from: https://pubmed.ncbi. nlm.nih.gov/26912151/.

17. Nayak G, Zhang KX, Vemaraju S, Odaka Y, Buhr ED, Holt-Jones A, et al. Adaptive Thermogenesis in Mice Is Enhanced by Opsin 3-Dependent Adipocyte Light Sensing. Cell Rep. Elsevier B.V.; 2020;30:672-686.e8. Available from: https://pubmed.ncbi.nlm. nih.gov/31968245/. 
18. Choi MS, Kim YJ, Kwon EY, Ryoo JY, Kim SR, Jung UJ. Highfat diet decreases energy expenditure and expression of genes controlling lipid metabolism, mitochondrial function and skeletal system development in the adipose tissue, along with increased expression of extracellular matrix remodelling- and inflamm. $\mathrm{Br}$ J Nutr. Cambridge University Press; 2015;113:867-77. Available from: https://pubmed.ncbi.nlm.nih.gov/25744306/.

19. Sato M, Tsuji T, Yang K, Ren X, Dreyfuss JM, Huang TL, et al. Cellautonomous light sensitivity via Opsin3 regulates fuel utilization in brown adipocytes. PLoS Biol. Public Library of Science; 2020;18. Available from: https://pubmed.ncbi.nlm.nih.gov/32040503/.

20. Wu AD, Dan W, Zhang Y, Vemaraju S, Upton BA, Lang RA, et al. Opsin 3-Gas promotes airway smooth muscle relaxation modulated by $\mathrm{G}$ protein receptor kinase 2 . Am J Respir Cell Mol Biol. American Thoracic Society; 2021;64:59-68. Available from: https://pubmed.ncbi.nlm.nih.gov/33058732/.

21. Regard JB, Sato IT, Coughlin SR. Anatomical Profiling of G Protein-Coupled Receptor Expression. Cell. Elsevier B.V.; 2008;135:561-71. Available from: /pmc/articles/PMC2590943/.

22. Rosell M, Kaforou M, Frontini A, Okolo A, Chan YW, Nikolopoulou $\mathrm{E}$, et al. Brown and white adipose tissues: Intrinsic differences in gene expression and response to cold exposure in mice. Am J Physiol Endocrinol Metab. 2014;306.

23. Ondrusova K, Fatehi M, Barr A, Czarnecka Z, Long W, Suzuki $\mathrm{K}$, et al. Subcutaneous white adipocytes express a light sensitive signaling pathway mediated via a melanopsin/TRPC channel axis. Sci Rep. Nature Publishing Group; 2017;7:1-9. Available from: https://www.nature.com/scientificreports/.

24. Zhang KX, D'Souza S, Upton BA, Kernodle S, Vemaraju S, Nayak G, et al. Violet-light suppression of thermogenesis by opsin 5 hypothalamic neurons. Nature. Nature Research; 2020;585:420 5. Available from: https://doi.org/10.1038/s41586-020-2683-0.

25. Opperhuizen AL, Stenvers DJ, Jansen RD, Foppen E, Fliers E, Kalsbeek A. Light at night acutely impairs glucose tolerance in a time-, intensityand wavelength-dependent manner in rats. Diabetologia. Springer Verlag; 2017;60:1333-43. Available from: https://pubmed.ncbi.nlm.nih.gov/ 28374068/.

26. Fonken LK, Nelson RJ. The effects of light at night on circadian clocks and metabolism. Endocr Rev. Endocrine Society; 2014. p. 648-70. Available from: https://pubmed.ncbi.nlm.nih.gov/24673 $196 /$.

27. Laermans J, Depoortere I. Chronobesity: Role of the circadian system in the obesity epidemic. Obes Rev. Blackwell Publishing Ltd; 2016;17:108-25. Available from: https://pubmed.ncbi.nlm. nih.gov/26693661/.

28. Milligan G, Alvarez-Curto E, Hudson BD, Prihandoko R, Tobin AB. FFA4/GPR120: Pharmacology and Therapeutic Opportunities. Trends Pharmacol Sci. Elsevier Ltd; 2017. p. 809-21. Available from: https://pubmed.ncbi.nlm.nih.gov/28734639/.

29. Hirasawa A, Tsumaya K, Awaji T, Katsuma S, Adachi T, Yamada $\mathrm{M}$, et al. Free fatty acids regulate gut incretin glucagon-like peptide-1 secretion through GPR120. Nat Med. Nat Med; 2005;11:904. Available from: https://pubmed.ncbi.nlm.nih.gov/15619630/.

30. Cartoni C, Yasumatsu K, Ohkuri T, Shigemura N, Yoshida R, Godinot N, et al. Taste preference for fatty acids is mediated by GPR40 and GPR120. J Neurosci. Society for Neuroscience; 2010;30:8376-82. Available from:/pmc/articles/PMC6634626/.

31. Matsumura S, Eguchi A, Mizushige T, Kitabayashi N, Tsuzuki S, Inoue $\mathrm{K}$, et al. Colocalization of GPR120 with phospholipase-C $\beta 2$ and $\alpha$-gustducin in the taste bud cells in mice. Neurosci Lett. Neurosci Lett; 2009;450:186-90. Available from: https://pubmed. ncbi.nlm.nih.gov/19071193/.

32. Oh DY, Talukdar S, Bae EJ, Imamura T, Morinaga H, Fan WQ, et al. GPR120 Is an Omega-3 Fatty Acid Receptor Mediating Potent Anti-inflammatory and Insulin-Sensitizing Effects. Cell. Department of Medicine, Division of Endocrinology and
Metabolism, University of California, San Diego, La Jolla, CA 92093, USA.; 2010;142:687-98. Available from: http://www.ncbi. nlm.nih.gov/pubmed/20813258.

33. Ichimura A, Hirasawa A, Poulain-Godefroy O, Bonnefond A, Hara $\mathrm{T}$, Yengo L, et al. Dysfunction of lipid sensor GPR120 leads to obesity in both mouse and human. Nature. 2012;483:350-4.

34. Quesada-López T, Cereijo R, Turatsinze JV, Planavila A, Cairó M, Gavaldà-Navarro A, et al. The lipid sensor GPR120 promotes brown fat activation and FGF21 release from adipocytes. Nat Commun. Nature Publishing Group; 2016;7.

35. Schilperoort M, Dam AD, Hoeke G, Shabalina IG, Okolo A, Hanyaloglu AC, et al. The GPR 120 agonist TUG -891 promotes metabolic health by stimulating mitochondrial respiration in brown fat. EMBO Mol Med. EMBO; 2018;10.

36. Quesada-López T, Gavaldà-Navarro A, Morón-Ros S, Campderrós L, Iglesias R, Giralt M, et al. GPR120 controls neonatal brown adipose tissue thermogenic induction. Am J Physiol Metab. NLM (Medline); 2019;317:E742-50. Available from: https://www.physiology.org/doi/https://doi.org/10.1152/ajpendo.00081.2019.

37. Husted AS, Ekberg JH, Tripp E, Nissen TAD, Meijnikman S, O'Brien SL, et al. Autocrine negative feedback regulation of lipolysis through sensing of NEFAs by FFAR4/GPR120 in WAT. Mol Metab. Elsevier GmbH; 2020;42. Available from: https:// pubmed.ncbi.nlm.nih.gov/33091626/.

38. Liu D, Costanzo A, Evans MDM, Archer NS, Nowson C, Duesing K, et al. Expression of the candidate fat taste receptors in human fungiform papillae and the association with fat taste function. Br J Nutr. Cambridge University Press; 2018;120:64-73. Available from: https:// pubmed.ncbi.nlm.nih.gov/29936924/.

39. Running CA, Craig BA, Mattes RD. Oleogustus: The unique taste of fat. Chem Senses. Oxford University Press; 2015;40:507-16. Available from: https://pubmed.ncbi.nlm.nih. gov/26142421/.

40. Bjursell M, Admyre T, Göransson M, Marley AE, Smith DM, Oscarsson $\mathrm{J}$, et al. Improved glucose control and reduced body fat mass in free fatty acid receptor 2-deficient mice fed a high-fat diet. Am J Physiol - Endocrinol Metab. Am J Physiol Endocrinol Metab; 2011;300. Available from: https://pubmed.ncbi.nlm.nih. gov/20959533/.

41. Kimura I, Ozawa K, Inoue D, Imamura T, Kimura K, Maeda T, et al. The gut microbiota suppresses insulin-mediated fat accumulation via the short-chain fatty acid receptor GPR43. Nat Commun. Nature Publishing Group; 2013;4:1829. Available from: / pmc/articles/PMC3674247/.

42. Louis P, Flint HJ. Formation of propionate and butyrate by the human colonic microbiota. Environ Microbiol. Blackwell Publishing Ltd; 2017. p. 29-41. Available from: https://pubmed.ncbi.nlm. nih.gov/27928878/.

43. Venegas DP, De La Fuente MK, Landskron G, González MJ, Quera R, Dijkstra G, et al. Short chain fatty acids (SCFAs)mediated gut epithelial and immune regulation and its relevance for inflammatory bowel diseases. Front Immunol. Frontiers Media S.A.; 2019. p. 277. Available from: https://www.frontiersin.org.

44. Chambers ES, Viardot A, Psichas A, Morrison DJ, Murphy KG, Zac-Varghese SEK, et al. Effects of targeted delivery of propionate to the human colon on appetite regulation, body weight maintenance and adiposity in overweight adults. Gut. BMJ Publishing Group; 2015;64:1744-54. Available from:https://doi.org/10.1136/ gutjnl-2014-307913.

45. Chambers ES, Byrne CS, Aspey K, Chen Y, Khan S, Morrison DJ, et al. Acute oral sodium propionate supplementation raises resting energy expenditure and lipid oxidation in fasted humans. Diabetes, Obes Metab. Blackwell Publishing Ltd; 2018;20:1034-9. Available from: https://pubmed.ncbi.nlm.nih.gov/29134744/.

46. Hu J, Kyrou I, Tan BK, Dimitriadis GK, Ramanjaneya M, Tripathi $\mathrm{G}$, et al. Short-chain fatty acid acetate stimulates adipogenesis 
and mitochondrial biogenesis via GPR43 in brown adipocytes. Endocrinology. Endocrine Society; 2016;157:1881-94. Available from: https://pubmed.ncbi.nlm.nih.gov/26990063/.

47. Sahuri-Arisoylu M, Brody LP, Parkinson JR, Parkes H, Navaratnam $\mathrm{N}$, Miller $\mathrm{AD}$, et al. Reprogramming of hepatic fat accumulation and "browning" of adipose tissue by the short-chain fatty acid acetate. Int J Obes. Nature Publishing Group; 2016;40:955-63. Available from: https://www.nature.com/ijo.

48. Avau B, Bauters D, Steensels S, Vancleef L, Laermans J, Lesuisse $\mathrm{J}$, et al. The gustatory signaling pathway and bitter taste receptors affect the development of obesity and adipocyte metabolism in mice. PLoS One. Public Library of Science; 2015;10. Available from: https://pubmed.ncbi.nlm.nih.gov/26692363/.

49. Ning $X, \mathrm{He} J$, Shi $X$, Yang G. Regulation of adipogenesis by quinine through the ERK/S6 pathway. Int J Mol Sci. MDPI AG; 2016;17. Available from: https://pubmed.ncbi.nlm.nih.gov/27089323/.

50. Cancello R, Micheletto G, Meta D, Lavagno R, Bevilacqua E, Panizzo V, et al. Expanding the role of bitter taste receptor in extra oral tissues: TAS2R38 is expressed in human adipocytes. Adipocyte. Taylor and Francis Inc.; 2020;9:7-15. Available from: https://pubmed.ncbi.nlm.nih.gov/31900035/.

51. Luo M, Ni K, Jin Y, Yu Z, Deng L. Toward the identification of extra-oral TAS2R agonists as drug agents for muscle relaxation therapies via bioinformatics-aided screening of bitter compounds in traditional Chinese medicine. Front Physiol. Frontiers Media S.A.; 2019. Available from: https://pubmed.ncbi.nlm.nih.gov/31379593/.

52. Kimura S, Kato E. TAS2R expression profile in brown adipose, white adipose, skeletal muscle, small intestine, liver and common cell lines derived from mice. Gene Reports. Elsevier Inc; 2020;20:100763.

53. Kochem M. Type 1 Taste Receptors in Taste and Metabolism. Ann Nutr Metab. S. Karger AG; 2017;70:27-36. Available from: https:// pubmed.ncbi.nlm.nih.gov/28903111/.

54. Murovets VO, Bachmanov AA, Zolotarev VA. Impaired glucose metabolism in mice lacking the Tas $1 \mathrm{r} 3$ taste receptor gene. PLoS One. Public Library of Science; 2015;10. Available from: https:// www.pubmed.ncbi.nlm.nih.gov/26107521/.

55. Glendinning JI, Gillman J, Zamer H, Margolskee RF, Sclafani A. The role of T1r3 and Trpm5 in carbohydrate-induced obesity in mice. Physiol Behav. Physiol Behav; 2012;107:50-8. Available from: https://pubmed.ncbi.nlm.nih.gov/22683548/.

56. Smith KR, Hussain T, Azari EK, Steiner JL, Ayala JE, Pratley RE, et al. Disruption of the sugar-sensing receptor T1R2 attenuates metabolic derangements associated with diet-induced obesity. Am J Physiol - Endocrinol Metab. American Physiological Society; 2016;310:E688-98. Available from: https://pubmed.ncbi.nlm.nih. gov/26884387/.

57. Simon BR, Learman BS, Parlee SD, Scheller EL, Mori H, Cawthorn WP, et al. Sweet taste receptor deficient mice have decreased adiposity and increased bone mass. PLoS One. Public Library of Science; 2014;9. Available from: https://pubmed.ncbi. nlm.nih.gov/24466105/.

58. Masubuchi Y, Nakagawa Y, Ma J, Sasaki T, Kitamura T, Yamamoto Y, et al. A Novel Regulatory Function of Sweet Taste-Sensing Receptor in Adipogenic Differentiation of 3T3-L1 Cells. PLoS One. PLoS One; 2013;8. Available from: https://pubmed.ncbi.nlm.nih.gov/23336004/.

59. Nakajima A, Nakatani A, Hasegawa S, Irie J, Ozawa K, Tsujimoto $\mathrm{G}$, et al. The short chain fatty acid receptor GPR43 regulates inflammatory signals in adipose tissue M2-type macrophages. Takahashi N, editor. PLoS One. Public Library of Science; 2017;12:e0179696. Available from: https://dx.plos.org/https://doi.org/10.1371/journal. pone. 0179696.

60. Hong Y-H, Nishimura Y, Hishikawa D, Tsuzuki H, Miyahara H, Gotoh C, et al. Acetate and Propionate Short Chain Fatty Acids Stimulate Adipogenesis via GPCR43. Endocrinology. Oxford
Academic; 2005;146:5092-9. Available from: https://academic. oup.com/endo/article/146/12/5092/2499972.

61. Frost G, Cai Z, Raven M, Otway DT, Mushtaq R, Johnston JD. Effect of short chain fatty acids on the expression of free fatty acid receptor 2 (Ffar2), Ffar3 and early-stage adipogenesis. Nutr Diabetes. Nature Publishing Group; 2014;4.

62. Muredda L, Kępczyńska MA, Zaibi MS, Alomar SY, Trayhurn P. IL-1 $\beta$ and TNF $\alpha$ inhibit GPR120 (FFAR4) and stimulate GPR84 (EX33) and GPR41 (FFAR3) fatty acid receptor expression in human adipocytes: implications for the anti-inflammatory action of n-3 fatty acids. Arch Physiol Biochem. Taylor and Francis Ltd; 2018;124:97-108. Available from: https://pubmed.ncbi.nlm.nih. gov/28835131/.

63. Quesada-López T, Cereijo R, Turatsinze JV, Planavila A, Cairó $\mathrm{M}$, Gavaldà-Navarro $\mathrm{A}$, et al. The lipid sensor GPR120 promotes brown fat activation and FGF21 release from adipocytes. Nat Commun. Nature Publishing Group; 2016;7. Available from: / pmc/articles/PMC5118546/.

64. Nagasaki H, Kondo T, Fuchigami M, Hashimoto H, Sugimura Y, Ozaki N, et al. Inflammatory changes in adipose tissue enhance expression of GPR84, a medium-chain fatty acid receptor: TNF $\alpha$ enhances GPR84 expression in adipocytes. FEBS Lett. FEBS Lett; 2012;586:368-72. Available from: https://pubmed.ncbi.nlm.nih. gov/22245676/.

65. Montgomery MK, Osborne B, Brandon AE, O'Reilly L, Fiveash $\mathrm{CE}$, Brown SHJ, et al. Regulation of mitochondrial metabolism in murine skeletal muscle by the medium-chain fatty acid receptor Gpr84. FASEB J. John Wiley and Sons Inc.; 2019;33:12264-76. Available from: https://pubmed.ncbi.nlm.nih.gov/31415180/.

66. Amisten S, Neville M, Hawkes R, Persaud SJ, Karpe F, Salehi A. An atlas of G-protein coupled receptor expression and function in human subcutaneous adipose tissue. Pharmacol Ther Elsevier BV. 2015;146:61-93.

67. Hauser AS, Attwood MM, Rask-Andersen M, Schiöth HB, Gloriam DE. Trends in GPCR drug discovery: New agents, targets and indications. Nat Rev Drug Discov. Nature Publishing Group; 2017;16:829 42. Available from: https://pubmed.ncbi.nlm.nih.gov/29075003/.

68. Suchý T, Zieschang C, Popkova Y, Kaczmarek I, Weiner J, Liebing $\mathrm{AD}$, et al. The repertoire of Adhesion $\mathrm{G}$ protein-coupled receptors in adipocytes and their functional relevance. Int J Obes. Springer Nature; 2020;44:2124-36. Available from: https://pubmed.ncbi. nlm.nih.gov/32203115/.

69. Forbes S, Stafford S, Coope G, Heffron H, Real K, Newman R, et al. Selective FFA2 agonism appears to act via intestinal PYY to reduce transit and food intake but does not improve glucose tolerance in mouse models. Diabetes. American Diabetes Association Inc.; 2015;64:3763-71. Available from: https://diabetes. diabetesjournals.org/content/64/11/3763.

70. Hudson BD, Due-Hansen ME, Christiansen E, Hansen AM, Mackenzie $\mathrm{AE}$, Murdoch $\mathrm{H}$, et al. Defining the molecular basis for the first potent and selective orthosteric agonists of the FFA2 free fatty acid receptor. J Biol Chem. Elsevier; 2013;288:17296-312. Available from: http:// www.jbc.org/article/S0021925820458740/fulltext.

71. Hansen AH, Sergeev E, Bolognini D, Sprenger RR, Ekberg JH, Ejsing CS, et al. Discovery of a Potent Thiazolidine Free Fatty Acid Receptor 2 Agonist with Favorable Pharmacokinetic Properties. J Med Chem. American Chemical Society; 2018;61:9534-50. Available from: https://pubs.acs.org/sharingguidelines.

72. Oh DY, Walenta E, Akiyama TE, Lagakos WS, Lackey D, Pessentheiner AR, et al. A Gpr120-selective agonist improves insulin resistance and chronic inflammation in obese mice. Nat Med. Nature Publishing Group; 2014;20:942-7. Available from: https://pubmed.ncbi.nlm.nih.gov/24997608/.

73. Bianchini G, Nigro C, Sirico A, Novelli R, Prevenzano I, Miele $\mathrm{C}$, et al. A new synthetic dual agonist of GPR120/GPR40 induces 
GLP-1 secretion and improves glucose homeostasis in mice. Biomed Pharmacother. Elsevier Masson s.r.1.; 2021;139:111613.

74. Carullo G, Mazzotta S, Vega-Holm M, Iglesias-Guerra F, VegaPerez JM, Aiello F, et al. GPR120/FFAR4 Pharmacology: Focus on Agonists in Type 2 Diabetes Mellitus Drug Discovery. J Med Chem. American Chemical Society; 2021. p. 4312-32. Available from: https://pubmed.ncbi.nlm.nih.gov/33843223/.

75. Brum MCB, Filho FFD, Schnorr CC, Bottega GB, Rodrigues TC. Shift work and its association with metabolic disorders. Diabetol Metab Syndr. BioMed Central Ltd.; 2015. Available from: /pmc/ articles/PMC4436793/.

76. Ozdeslik RN, Olinski LE, Trieu MM, Oprian DD, Oancea E, Yau -W. Human nonvisual opsin 3 regulates pigmentation of epidermal melanocytes through functional interaction with melanocortin 1 receptor; Available from: https://doi.org/10.1073/pnas.1902825116.

77. Hoch M, Eberle AN, Wagner U, Bussmann C, Peters T, Peterli R. Expression and Localization of Melanocortin-1 Receptor in Human Adipose Tissues of Severely Obese Patients*. Obesity. John Wiley \& Sons, Ltd; 2007;15:40-9. Available from: https:// doi.org/10.1038/oby.2007.525.

Publisher's Note Springer Nature remains neutral with regard to jurisdictional claims in published maps and institutional affiliations. 